Keywords: Schizophrenia; Th2; Cytokine; IFNgamma; IL-4; IL-10.

\title{
In vivo type II T-helper cells shift in schizophrenia compared to sex- and age-matched healthy controls
}

\author{
Sonnig Sue Whei Chiang \\ Michael Riedel \\ Rudolf Gruber \\ Norbert Müller \\ Markus Schwarz
}

Psychiatric Hospital of Munich University, Munich

Institute of Cognitive Neuroscience of National Central University, Taiwan

GERMANY

CHINA

\begin{abstract}
Background and Objectives: Over-production of the type II T-helper cells (Th2-shfit) has been suggested as a candidate mechanism for the etiology in at least one subgroup of schizophrenia. Hitherto, empirical evidence is derived mostly from in vitro cytokine production. Due to frequently undetectable serum levels of the major Th2 cytokine Interleukin-4 (IL-4), direct evidence, measured as a ratio between Th1/Th2 (type I/type II Thelper cells) characteristic cytokines, is rare. This study aimed at examining whether a serum Th2-shift occurs in schizophrenia. Th2-shift was defined as markedly decreased serum IFN$\gamma / \mathrm{IL}-4$ and/or IFN- $\gamma / \mathrm{IL}-10$ and/or IL-2/IL-4 ratios, compared with healthy subjects.

Methods: Totally 74 subjects were recruited: 37 drug-free subjects with schizophrenia according to ICD-10 and DSM-IV as well as 37 age- and sex-matched healthy controls. Cytometric Bead Array, which enables a simultaneous measurement of 6 cytokines with the same volume of test sample, was used to assess serum Th1/Th2 ratios and cytokine levels. Non-parametric Mann-Whitney U test was utilized to detect the diversities in serum Th1/Th2 ratios and cytokine levels between both diagnostic groups.

Results: Subjects with schizophrenia showed significantly reduced serum IFN- $\gamma / \mathrm{IL}-4$ and IFN- $\gamma /$ IL-10 ratios if compared to healthy controls. If both sexes analyzed separately, males with schizophrenia had significantly reduced serum IFN- $\gamma /$ IL-10 ratios, while female patients showed markedly decreased serum IFN- $\gamma /$ IL-4 ratios.

Conclusions: A clear Th2-shift was observed in schizophrenia. Males and females with schizophrenia seemed to have different profiles of Th2-shift. Th1/Th2 ratios appeared to play different roles in the pathology of males and females with schizophrenia.
\end{abstract}

Received: 26 May 2010

Revised: 21 April 2011

Accepted: 29 April 2011 


\section{Introduction}

Immune dysfunction is thought to link to the pathomechanism of schizophrenia ${ }^{1}$. Epidemiological studies relating to antibody titers against various viruses indicate that viral infection could be the cause of immune dysfunction in one subgroup of schizophren$\mathrm{ics}^{2}$. Several viral infections have been associated with the risk of this disorder ${ }^{3-5}$. During antiviral immunity, accurate control of the balance between the type I and type II Thelper cells (Th1 and Th2) is pivotal for optimizing immune response ${ }^{6}$. As a result of host defense against diverse viral infections and protective mechanisms from autoimmunity, Th1/Th2 imbalance was often implicat$\mathrm{ed}^{7-9}$. Th1 cells mainly produce interferongamma (IFN- $\gamma$ ), interleukin-2 (IL-2), and tumor necrosis factor-a (TNF- $\alpha$ ), while Th2 lymphocytes predominantly release interleukin-4 (IL-4), interleukin-10 (IL-10), and interleukin-6 (IL-6) ${ }^{10-12}$.

In vivo serum data reflect the possible cumulative effects of diverse biological systems. Although they show that subjects with schizophrenia had comparable serum IL$2^{13-16}$, TNF- $\alpha^{17-23}$, IL-4 ${ }^{16}$, IL-10 24 , and IFN$\gamma^{13,25-27}$ levels with healthy controls, much more empirical findings concerning the major Th1 cytokine, IFN- $\gamma$, in vitro production $^{16,28-35}$ and Th2 cytokine, IL-6, serum, plasma, and CSF levels ${ }^{16,17,36-46}$ revealed under-production of Th1-cytokines, however, over-production of Th2-cytokines in schizophrenia. They suggest a possible Th1/Th2 imbalance in schizophrenia. Th2shift was therefore speculated as a potential cause of schizophrenic symptoms in at least one subgroup of schizophrenia ${ }^{47-49}$.

Empirical studies examining individual Th1/Th2 cytokines in schizophrenia are plenty, while those investigating the ratios between the in vivo levels of major Th1/ Th2 cytokines are rare. Due to the inhibitory effects of IL- $10^{50}$ and IL-4 ${ }^{51}$ on Th1 cells, IFN- $\gamma^{52}$ on Th2 cells as well as the role of IL- $4^{53}$ in Th2 and IFN- $\gamma^{54}$ in Th1 development, IFN- $\gamma / \mathrm{IL}-4^{55}$ and IFN- $\gamma / \mathrm{IL}-10$ ratios $^{55}$ have been frequently used to examine Th1/Th2 immunity. Up to date, only two studies $^{56,57}$ examined IFN- $\gamma /$ IL-4 ratios in schizophrenia; one found unaltered in-vitro IFN- $\gamma / \mathrm{IL}-4$ ratios, while the other showed increased in-vivo ones. In this study, we attempted, based on evidence from studies on individual Th1/Th2 cytokines, to examine whether in vivo Th2-shift, defined as remarkably reduced serum IFN- $\gamma / \mathrm{IL}-4$ and/or IFN- $\gamma /$ IL-10 ratios, occurred in schizophrenia since they are regarded as indicators of Th1/Th2 balance ${ }^{58,59}$ due to their roles in the differentiation and development of the Th1/Th2 systems. In addition, IL-2 and IL-4 may regulate Th1/Th2 balance and activity in brain function ${ }^{60}$. Thus, the IL-2/IL-4 ratios were also examined.

\section{Methods}

\section{Participants}

Thirty-seven subjects with schizophrenia and 37 healthy controls were recruited. Each group consists of 14 females and 23 males. After the aim of the study fully explained, they had given their written informed consent for participating in this study. The obligatory inclusion criteria for all participants were: free of any severe medical diseases, acute allergies, inflammatory disorders, autoimmune diseases, and clinically apparent infections. These were controlled through conducting thoroughly laboratory and medical examinations. Further crucial criteria for subjects with schizophrenia in- 
cluded: (1) neuroleptic-free for at least 7 days, (2) a schizophrenia diagnosis in accordance with ICD-10 ${ }^{61}$ and DSM-IV ${ }^{62}$, (3) no history of psychotropic substance addiction or abuse except nicotine, and (4) no personality disorders according to DSM-IV. Two other important inclusion criteria for healthy controls to fulfill were (1) no psychiatric disorders and (2) no first-degree biological relatives who had (had) any psychiatric diseases. The Positive and Negative Syndrome Scale (PANSS) ${ }^{63}$ was used to assess the psychopathology of subjects with schizophrenia. Symptom severity of subjects with schizophrenia was measured by using the Clinical Global Impression (CGI) ${ }^{64}$.

\section{Cytokine assessments}

Serum of each subject was drawn between 8-9 AM, then immediately centrifuged at $6^{\circ} \mathrm{C}$ with a speed of $3200^{\prime} \mathrm{g}$ for 10 minutes, finally frozen at $-80^{\circ} \mathrm{C}$ until analysis. The Human Th1/Th2 Cytokine Cytometric Bead Array (CBA) Kit-II (Becton Dickinson Pharmingen, USA) was applied to detect Th1/ Th2 cytokines including IFN- $\gamma$, IL- 2 , TNF$\alpha$, IL-4, IL-10, and IL-6. CBA is an ELISAvariant, and is measured by flow cytometry. CBA is as specific and sensitive as ELISA. Both methods share many similarities, including the working mechanism - the antibody-cytokine-antibody sandwich principal. The main reason to choose CBA, instead of conventional ELISA, was the comparability among distinct cytokines measured is higher in CBA than that in ELISA since diverse cytokines of the same individual can be detected with the same test sample. That is, there is no inter-assay variance among distinct cytokines of the same subject. It is, therefore, particularly proper to scrutinize IFN- $\gamma / \mathrm{IL}-4$, IFN- $\gamma / \mathrm{IL}-10$, and IL-2/IL-4 ratios. The whole procedure to measure cytokines was conducted as the manual describes except the volumes of serum, capture bead mixture, and phycoerythrin (PE) detection reagent. Instead of $50 \mathrm{ml}, 100 \mathrm{ml}$ of each was used. In addition, the bottom standard was diluted to 2 levels lower than that described in the manual to detect serum IL-4 and IL-2 levels in all cases. According to the information given by the manufacturer, the intra-assay coefficients of variance for IL-2, IL-4, IL-6, IL-10, TNF-a, and IFN- $\gamma$ are 4$5 \%, 2-5 \%, 4-6 \%, 4-5 \%, 6-8 \%$, and $3-4 \%$, while those inter-assay ones are 7-9\%, 5$11 \%, 7-13 \%, 6-11 \%, 8-12 \%$, and $8-11 \%$, correspondingly.

\section{Experimental design and statistics}

The independent variable was diagnostic group (schizophrenia vs. healthy controls). The major dependent variables contained serum Th1/Th2 ratios and various cytokine levels. The discrepancies between both diagnostic groups in age, onset age, hospitalization length, illness duration, the scores of PANSS scales, and those of CGI were examined by using student T-tests. Spearman correlations were applied to examine the associations between Th1/Th2 cytokines/ratios, psychopathology, and symptom severity, whereas Pearson correlations were used to check the relationships of Th1/Th2 cytokines/ratios to hospitalization and illness duration. Non-parametric Mann-Whitney U tests were conducted to detect the differences in serum Th1/Th2 ratios and cytokine levels. The data were evaluated by conducting SPSS (Version 11.5). 


\section{Results}

\section{Demographical and clinical data}

Totally, 74 subjects (age range: $18-60$ years old) had participated into this study. Thirty-seven of them were subjects with schizophrenia. The remaining 37 were healthy controls. Each group contained 23 males and 14 females. On average, the patient and control groups were 31.65 (SD = $11.22)$ and $31.70(\mathrm{SD}=11.13)$ years old, correspondingly. No remarkable differences in age were shown $(\mathrm{t}=-0.02, \mathrm{df}=72, \mathrm{p}=$ 0.98 ). Similarly, between both male and both female subgroups demonstrated likewise no diversities (male: $\mathrm{t}=-0.01, \mathrm{df}=44, \mathrm{p}=0.99$; female: $\mathrm{t}=-0.02, \mathrm{df}=26, \mathrm{p}=0.99)$. The mean ages of both male subgroups were 31.13 $(\mathrm{SD}=11.27)$ and $31.17(\mathrm{SD}=11.10)$, while these for female patients and controls were $32.50(\mathrm{SD}=11.53)$ and $32.57(\mathrm{SD}=11.53)$ years old, respectively. Among the 23 males with schizophrenia, 15 were paranoid schiz- ophrenia, 4 disorganized schizophrenia, 3 catatonic schizophrenia, and 1 schizoaffective disorder. Among the 14 female subjects with schizophrenia, there were 12 paranoid schizophrenia, 1 disorganized schizophrenia, and 1 catatonic schizophrenia according to DSM-IV. Data regarding onset age, hospitalization length, illness duration, PANSS, and CGI scores of some patients were missing; thus, results in these regards concerned only one part of the subjects with schizophrenia. The means for the PANSS positive scale (PANSS P), the negative scale (PANSS $\mathrm{N}$ ), the general psychopathology scale (PANSS G), the CGI scores at admission (CGI-A) and at discharge (CGI-D) as well as differences between admission and discharge (CGI-diff) in subjects with schizophrenia are summarized in Table 1. Both males and females with schizophrenia were similar in terms of psychopathology, symptom severity, hospitalization, onset age, and illness duration (PANSS P: $\mathrm{t}=-1.54$, $\mathrm{df}=$ $23, \mathrm{p}=0.14 ;$ PANSS N: $\mathrm{t}=0.91, \mathrm{df}=23, \mathrm{p}=$

Table 1

Clinical data of subjects with schizophrenia. Summary of the means (M) and standard deviations (SD) of the clinical data, psychopathology, symptom severity in subjects with schizophrenia

\begin{tabular}{|c|c|c|c|c|c|c|}
\hline & \multicolumn{2}{|c|}{ Male + female } & \multicolumn{2}{|c|}{ Male } & \multicolumn{2}{|c|}{ Female } \\
\hline & M & $\mathrm{SD}$ & M & $\mathrm{SD}$ & M & SD \\
\hline Onset age & 26.50 & 9.61 & 26.20 & 10.65 & 27.00 & 8.16 \\
\hline Hospital & 8.19 & 6.02 & 8.17 & 6.60 & 8.23 & 5.10 \\
\hline Ill_dur & 5.67 & 8.68 & 4.80 & 8.44 & 7.11 & 9.37 \\
\hline PANSS P & 22.40 & 5.45 & 21.07 & 5.55 & 24.40 & 4.90 \\
\hline PANSS N & 26.24 & 10.04 & 27.73 & 10.95 & 24.00 & 8.54 \\
\hline PANSS G & 49.12 & 14.12 & 51.47 & 14.84 & 45.60 & 12.88 \\
\hline CGI-A & 5.73 & 0.78 & 5.69 & 0.79 & 5.80 & 0.79 \\
\hline CGI-D & 3.62 & 1.58 & 3.38 & 1.54 & 4.00 & 1.63 \\
\hline CGI-diff & 2.12 & 1.40 & 2.31 & 1.58 & 1.80 & 1.03 \\
\hline
\end{tabular}

Note: Onset age: years old; Hospital = hospitalization length (weeks); ill_dur = illness duration (years); PANSS $=$ the Positive and Negative Syndrome Scale; PANSS P = The Positive Scale of PANSS; PANSS N = the negative Scale of PANSS; PANSS G = The General Psychopathology Scale of PANSS; CGI = the Clinical Global Impression of Severity; CGI-A = the CGI score at admission; CGI-D = the CGI score at discharge; CGI-diff $=$ the CGI score difference between admission and discharge. 
0.37; PANSS G: $\mathrm{t}=1.02, \mathrm{df}=23, \mathrm{p}=0.32$; CGI-A: $\mathrm{t}=-0.35, \mathrm{df}=24, \mathrm{p}=0.73$; CGI-D: $\mathrm{t}=$ $-0.98, \mathrm{df}=24, \mathrm{p}=0.34$; CGI-diff: $\mathrm{t}=0.91, \mathrm{df}=$ $24, \mathrm{p}=0.37$; hospitalization: $\mathrm{t}=-0.23, \mathrm{df}=34$, $\mathrm{p}=0.98$; onset age: $\mathrm{t}=-0.19, \mathrm{df}=22, \mathrm{p}=0.85$; illness duration: $\mathrm{t}=-0.62, \mathrm{df}=22, \mathrm{p}=0.54$ ).

\section{Th1/Th2 ratios and cytokines}

After doubling the volumes of the reagents and serum samples and lowering the bottom standard, the cytokine levels of all subjects were detectable. The data regarding serum Th1/Th2 ratios and cytokine levels in subjects with schizophrenia and healthy controls are summarized in Table 2.
Subjects with schizophrenia vs. healthy controls

At individual serum cytokine levels, subjects with schizophrenia as a whole group had lower average serum IFN- $\gamma$, IL- 2 , and IL-4 levels, but higher average serum IL-6, IL-10, and TNF- $\alpha$ levels. However, the means of all Th1/Th2 ratios examined in subjects with schizophrenia were lower than those of their healthy counterparts. Nonparametric Mann-Whitney U tests revealed that schizophrenic subjects had significantly lower serum IFN- $\gamma / \mathrm{IL} 4$ and IFN- $\gamma /$ IL10 ratios, but showed markedly higher IL-6 levels than did healthy controls (IFN- $\gamma /$ IL4: $\mathrm{Z}=$ $-2.01, \mathrm{p}=0.05 ; \mathrm{IFN}-\gamma / \mathrm{IL} 10: \mathrm{Z}=-2.35, \mathrm{p}=$

Table 2

Serum Th1/Th2 cytokine levels and ratios. Summary of the means (M) and standard deviations (SD) of serum Th1/Th2 cytokines and ratios in subjects with schizophrenia ( $\mathrm{SCH})$ and healthy controls $(\mathrm{CON})$

\begin{tabular}{|c|c|c|c|c|c|c|}
\hline \multirow{2}{*}{$\frac{M}{(\mathrm{SD})}$} & \multicolumn{2}{|c|}{ Male + female } & \multicolumn{2}{|c|}{ Male } & \multicolumn{2}{|c|}{ Female } \\
\hline & $\mathrm{SCH}(\mathrm{N}=37)$ & $\mathrm{CON}(\mathrm{N}=37)$ & $\mathrm{SCH}(\mathrm{N}=23)$ & $\mathrm{CON}(\mathrm{N}=23)$ & $\mathrm{SCH}(\mathrm{N}=14)$ & $\mathrm{CON}(\mathrm{N}=14)$ \\
\hline \multirow[t]{2}{*}{ IL-2/IL-4 } & 0.65 & 0.72 & 0.73 & 0.66 & 0.51 & 0.83 \\
\hline & $(0.30)$ & $(0.45)$ & $(0.34)$ & $(0.38)$ & $(0.17)$ & $(0.54)$ \\
\hline \multirow[t]{2}{*}{ IFN/IL-4 } & $13.18 *$ & 18.51 & 14.85 & 18.94 & $10.44 *$ & 17.80 \\
\hline & (7.64) & (11.45) & $(8.42)$ & (12.61) & $(5.37)$ & $(9.63)$ \\
\hline \multirow[t]{2}{*}{ IFN/IL-10 } & $14.80 *$ & 19.71 & $14.99 *$ & 20.89 & 14.48 & 17.78 \\
\hline & $(7.91)$ & $(10.25)$ & $(8.59)$ & (11.35) & $(6.95)$ & $(8.14)$ \\
\hline \multirow[t]{2}{*}{ IFN } & 39.27 & 50.54 & $40.99 *$ & 57.81 & 36.44 & 38.61 \\
\hline & (21.39) & $(28.56)$ & $(25.03)$ & (32.73) & (13.89) & (14.08) \\
\hline \multirow[t]{2}{*}{ TNF- $\alpha$} & 1.86 & 1.77 & 1.77 & 1.82 & 1.99 & 1.68 \\
\hline & $(0.48)$ & $(0.49)$ & $(0.36)$ & $(0.57)$ & $(0.62)$ & $(0.33)$ \\
\hline \multirow[t]{2}{*}{ IL-2 } & 1.92 & 1.96 & 2.00 & 2.08 & 1.78 & 1.77 \\
\hline & $(0.65)$ & $(0.95)$ & $(0.76)$ & $(1.12)$ & $(0.42)$ & $(0.55)$ \\
\hline \multirow[t]{2}{*}{ IL-4 } & 3.28 & 3.40 & 3.02 & 3.78 & $3.73 *$ & 2.77 \\
\hline & (1.14) & $(2.17)$ & $(1.06)$ & $(2.40)$ & $(1.15)$ & $(1.62)$ \\
\hline \multirow[t]{2}{*}{ IL-6 } & $3.60 *$ & 2.48 & 2.74 & 2.69 & $5.02 *$ & 2.14 \\
\hline & $(5.42)$ & (1.61) & (1.03) & $(1.88)$ & $(8.71)$ & $(1.01)$ \\
\hline \multirow[t]{2}{*}{ IL-10 } & 2.83 & 2.77 & 2.88 & 3.07 & 2.75 & 2.28 \\
\hline & (1.23) & (1.51) & (1.27) & $(1.80)$ & (1.19) & $(0.64)$ \\
\hline
\end{tabular}

Note: IFN $=$ IFN- $\gamma ; * \mathrm{p} \leq 0.05$. 
0.02 ; IL-6: $\mathrm{Z}=-2.34, \mathrm{p}=0.02)$. Apart from these marked diversities mentioned above, none of the rest serum Th1/Th2 parameters examined in this study achieved a statistic significance level (IL-2/IL-4: $\mathrm{Z}=-0.44, \mathrm{p}=$
$0.66 ;$ IFN- $\gamma: Z=-1.82, p=0.07 ; \mathrm{IL}-2: \mathrm{Z}=$ $-0.35, \mathrm{p}=0.73$; TNF- $\alpha: \mathrm{Z}=-0.89, \mathrm{p}=0.37$; IL-10: $Z=-0.79, p=0.43 ;$ IL-4: $Z=-0.41, p$ $=0.68)$.

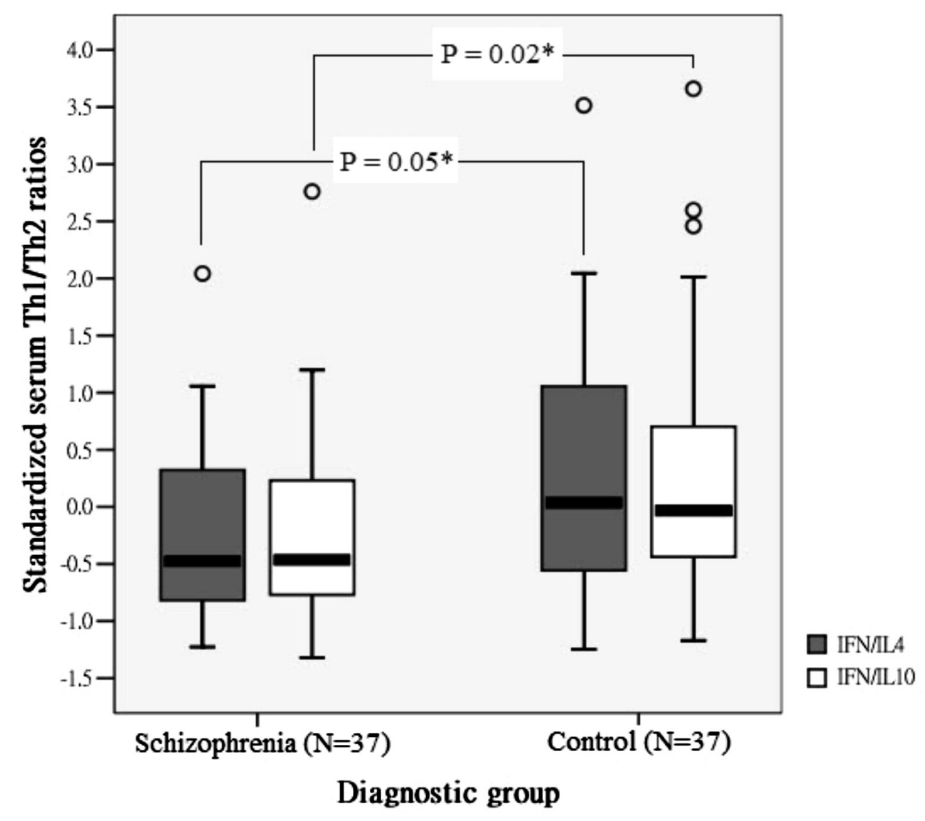

Figure 1. Significantly reduced serum Th1/Th2 ratios in schizophrenia. Box-plots of the standardized serum Th1/Th2 ratios in subjects with schizophrenia and healthy controls show the medians, quartiles, and outliers (IFN/IL4 = IFN- $\gamma /$ IL-4 $=$ gray box, $\mathrm{N}=37$; IFN/IL10 $=$ IFN- $\gamma / \mathrm{IL}-10=$ white box, $\mathrm{N}=37$; the box $=$ inter the 25 th and 75 th percentile range; cross-box line $=$ the median; lower bar $=$ the 25 th percentile; upper bar $=$ the 75 th percentile $; \mathrm{O}=$ outliers; $* \mathrm{p} \leq .05)$

Males with schizophrenia vs. male controls

If compared to male healthy controls, males with schizophrenia had significantly lower serum IFN- $\gamma$ levels and IFN- $\gamma / \mathrm{IL}-10$ ratios (IFN- $\gamma: \mathrm{Z}=-2.19, \mathrm{p}=0.03$; IFN- $\gamma / \mathrm{IL}-$ $10: \mathrm{Z}=-1.99, \mathrm{p}=0.05)$. However, both male subgroups had similar IL-2/IL-4, IFN/IL-4 ratios, TNF-a, IL-2, IL-4, IL-6, and IL-10 levels (IL-2/IL-4: $\mathrm{Z}=-0.80, \mathrm{p}=0.42$; IFN- $\gamma / \mathrm{IL}-4: \mathrm{Z}=-0.89, \mathrm{p}=0.37 ; \mathrm{IL}-2: \mathrm{Z}=-0.41$, $\mathrm{p}=0.68 ; \mathrm{IL}-4: \mathrm{Z}=-1.29, \mathrm{p}=0.20 ; \mathrm{IL}-6: \mathrm{Z}=$ $-1.33, \mathrm{p}=0.18$; IL-10: $\mathrm{Z}=-0.04, \mathrm{p}=0.97$ ).

Females with schizophrenia vs. female controls

Nevertheless, the comparisons between both female subgroups demonstrated that female schizophrenia had significantly higher serum IL-4 and IL-6 levels, but had markedly lower IFN- $\gamma /$ IL-4 ratios than did healthy 
females (IL-4: $\mathrm{Z}=-2.21, \mathrm{p}=0.03$; IL-6: $\mathrm{Z}=$ $-1.98, \mathrm{p}=0.05 ; \mathrm{IFN}-\gamma / \mathrm{IL}-4: \mathrm{Z}=-2.11, \mathrm{p}=$ $0.04)$. But both female subgroups were comparable in terms of IL-2/IL-4, IFN- $\gamma / \mathrm{IL}-10$ ratios, IFN- $\gamma$, TNF-a, IL-2, and IL-10 levels (IL-2/IL-4: $Z=-1.42, p=0.15$; IFN- $\gamma /$ IL-10: $\mathrm{Z}=-1.15, \mathrm{p}=0.25 ;$ IFN- $\gamma: \mathrm{Z}=0.00, \mathrm{p}=$ 1.00 ; TNF-a: $\mathrm{Z}=-1.24, \mathrm{p}=0.22$; IL-2: $\mathrm{Z}=$ $-0.28, p=0.78 ;$ IL-10: $Z=-1.06, p=0.29$ ).

\section{Th1/Th2 ratios and clinical symptoms}

The correlations between $\mathrm{Th} 1 / \mathrm{Th} 2$ ratios and psychopathology as well as symptom severity are summarized in Table 3 . According to the data available in this study, none of the Th1/Th2 ratios significantly correlat- ed with any scores of PANSS or CGI in schizophrenia as a whole group. If only male schizophrenia considered, then the IL2/IL-4 ratios were positively associated with both the PANSS negative syndrome subscale $(\mathrm{R}=0.55, \mathrm{p}=0.04)$ and the general psychopathology subscale $(\mathrm{R}=0.54, \mathrm{p}=$ $0.04)$, while the IFN- $\gamma / \mathrm{IL}-10$ ratios were positively related to the CGI scores at discharge $(\mathrm{R}=0.52, \mathrm{p}=0.04)$. In female schizophrenia, none of the Th1/Th2 ratios significantly correlated with any scores of PANSS scales. However, the IFN- $\gamma / \mathrm{IL}-10$ ratios in females with schizophrenia were negatively associated with the CGI scores at admission $(\mathrm{R}=$ $0.75, \mathrm{p}=0.01)$ and at discharge $(\mathrm{R}=-0.79, \mathrm{p}$ $=0.006$ ), but were positively correlated with the CGI score differences/changes between admission and discharge $(R=0.64, p=0.05)$.

Table 3

Correlations between Th1/Th2 ratios and psychopathology. Summary of correlations between Th1/Th2 ratios and psychopathology (measured with PANSS) and symptom severity (measured with CGI) in schizophrenia

\begin{tabular}{lcccccc}
\multicolumn{3}{c}{ PANSS $(\mathrm{N}=25)$} & \multicolumn{3}{c}{ CGI (N=26) } \\
\hline Male + Female & Positive & Negative & General & Admission & Discharge & Difference \\
\hline IL-2/IL-4 & 0.00 & 0.35 & 0.34 & 0.27 & 0.18 & -0.10 \\
IFN/IL-4 & -0.34 & 0.14 & 0.17 & -0.07 & 0.09 & -0.14 \\
IFN/IL-10 & -0.11 & 0.10 & 0.07 & -0.22 & -0.03 & -0.03 \\
\hline
\end{tabular}

\begin{tabular}{|c|c|c|c|c|c|c|}
\hline & \multicolumn{3}{|c|}{ PANSS $(\mathrm{N}=15)$} & \multicolumn{3}{|c|}{ CGI (N=16) } \\
\hline Male & Positive & Negative & General & Admission & Discharge & Difference \\
\hline IL-2/IL-4 & 0.08 & $0.55 *$ & $0.54 *$ & 0.17 & 0.10 & -0.02 \\
\hline IFN/IL-4 & -0.30 & 0.22 & 0.16 & 0.06 & 0.41 & -0.38 \\
\hline \multirow[t]{2}{*}{ IFN/IL-10 } & -0.10 & 0.21 & 0.08 & 0.21 & $0.52 *$ & -0.47 \\
\hline & \multicolumn{3}{|c|}{ PANSS $(\mathrm{N}=10)$} & \multicolumn{3}{|c|}{ CGI (N=10) } \\
\hline Female & Positive & Negative & General & Admission & Discharge & Difference \\
\hline IL-2/IL-4 & 0.40 & -0.08 & -0.08 & 0.51 & 0.45 & -0.26 \\
\hline IFN/IL-4 & -0.23 & -0.10 & 0.07 & -0.25 & -0.33 & 0.37 \\
\hline IFN/IL-10 & -0.46 & -0.13 & 0.06 & $-0.75 * *$ & $-0.79 * *$ & $0.64 *$ \\
\hline
\end{tabular}

Note: PANSS $=$ The Positive and Negative Syndrome Scale; Positive = Positive Scale; Negative = Negative Scale; General = General Psychopathology Scale $;$ CGI $=$ The Clinical Global Impression $;$ Admission $=$ at admission; Discharge $=$ at discharge; Difference $=$ difference between at admission \& discharge; IFN $=$ IFN- $\gamma$. 


\section{Th1/Th2 ratios and illness duration/hospitalization}

However, none of the Th1/Th2 ratios and serum cytokine levels examined in this study significantly correlated with illness duration and hospitalization length, regardless of patients' genders. Due to the space limit of this report, detailed results in these regards are available on request.

\section{Conclusions}

A clear in vivo Th2-shift was observed in our drug-free patients with schizophrenia, showing significantly reduced serum IFN$\gamma / \mathrm{IL}-4$ and IFN- $\gamma / \mathrm{IL}-10$ ratios. At the individual cytokine levels, schizophrenia as a whole group also showed significantly higher serum IL-6 levels than did healthy controls. If both sexes analyzed separately, the Th1/Th2 dysfunction profiles of male and female schizophrenia were different. Male subjects with schizophrenia revealed significantly lower serum IFN- $\gamma / \mathrm{IL}-10$ ratios and IFN- $\gamma$ levels, whereas female subjects with schizophrenia showed markedly lower serum IFN- $\gamma /$ IL-4 ratios, but had significantly higher serum IL-4 and IL-6 levels.

At individual cytokine levels, our findings generally correspond to the majority of relevant literature showing increased serum IL$6^{22,40-43,45,65-70}$, unaltered serum IL-2 $13,18,26,71$, TNF- $\alpha^{17-20,22,43,71}$, IFN- $\gamma^{13,27,57}$, IL-4 ${ }^{24,70}$, and IL-10 24 levels in schizophrenia as a whole group. It's noteworthy that although recent evidence showing intense exercise transiently increases IL- $6^{72}$, blood samples of our subjects were collected between 8-9am without any exercise. Therefore, increased serum IL-6 levels in our schizophrenic subjects were not results of exercise. Decreased serum IFN- $\gamma$ levels in our schizophrenic males could be genetically determined since Freudenreich et al..$^{73}$ included almost only (86.7\%) males with schizophrenia and found significantly reduced IFN- $\gamma$ mRNA in schizophrenia. Increased serum IL-4 levels in our schizophrenic females might be related to the pathology since IL-4 is able to regulate brain activity ${ }^{60}$. However, IL-4 could also influence the pathology through its impact on IFN- $\gamma /$ IL-10 and IL-2/IL-4 balance since serum IFN- $\gamma / \mathrm{IL}-10$ balance were related to symptom severity in females and IL2/IL-4 ratios to negative symptoms/psychopathology in males with schizophrenia, but not it per se. Diversities between some other studies $15,18,20,21,24,26,41,68,71,74$ and ours may be raised by different gender distributions and/or average ages since (1) gender dimorphism during immune responses was observed $^{75}$ and (2) cytokine levels could vary in age-related manner ${ }^{20,76}$. The subjects of those studies were either not exactly sex- and/or age-matched or averagely much older than ours. Due to limited space and the main focus of this study, more detailed comparisons at individual cytokine levels won't be described here.

Studies directly examining Th1/Th2 ratios in schizophrenia are rare. So far no findings regarding serum IL-2/IL-4 ratios in schizophrenia were reported. Although serum IL-2/IL-4 ratios were found unchanged in our subjects with schizophrenia, they were related to negative symptoms and psychopathology in males, but not in females, with schizophrenia. The reason why our subjects with schizophrenia showing unaltered serum IL-2/IL-4 ratios could be that our patients were relatively selective and not predominated with negative symptoms since (1) persistent negative symptoms result in long-term disability ${ }^{77}$ and (2) those patients participated in our study must have 
relatively good responsiveness to give their consents and to be interviewed. Balance between IL-2 and IL-4 could be involved in general psychopathology in males with schizophrenia since IL-2 is likely, as shown in previous studies, associated with positive/negative symptoms ${ }^{74,78,79}$.

So far, only Avgustin ${ }^{56}$ and $\mathrm{Kim}^{57}$ examined IFN- $\gamma /$ IL-4 ratios in schizophrenia. In contrast to our finding, Avgustin found no differences in in-vitro IFN- $\gamma / \mathrm{IL}-4$ ratios between schizophrenia and healthy controls, while Kim reported higher plasma IFN$\gamma /$ IL-4 ratios in schizophrenia. Although invitro production IFN- $\gamma / \mathrm{IL}-4$ ratios are related to in-vivo serum IFN- $\gamma / \mathrm{IL}-4$ ratios, both could be different due to distinct biological systems involved and interactions occurred and are thus not necessarily similar. This is likely the main reason why we had different result from that of Avgustin. Contrary to that study of Kim, we applied a modified Cytometric Bead Array to measure cytokines (using flow cytometry) and did not have missing data. The results of Kim's study might be the outcomes of selection because they had some subjects showing cytokine levels under the detectable limits and excluded into the analyses. Another reason might be different male/female ratios in both studies due to gender dimorphism during immune responses ${ }^{75}$, a role of sex hormones in regulating immunity including Th1/Th2 balance ${ }^{80}$, and significantly higher IFN- $\gamma / \mathrm{IL}-$ 4 ratios in men ${ }^{81}$. Besides, the subjects with schizophrenia in Kim's study were possibly predominated with negative symptoms since significantly higher IFN- $\gamma / \mathrm{IL}-4$ ratios were recently observed in depression ${ }^{82}$. This is the first study reporting significantly reduced serum IFN- $\gamma /$ IL-4 in schizophrenic females. However, no links between serum IFN- $\gamma / \mathrm{IL}-$ 4 ratios and psychopathology or symptom severity were found. Maybe significantly re- duced IFN- $\gamma / \mathrm{IL}-4$ ratios are rather trait markers than state markers for schizophrenic females; they might be the basis of IFN$\gamma / \mathrm{IL}-10$ imbalance in schizophrenia.

Up to date, we are the first group examining serum IFN- $\gamma / \mathrm{IL}-10$ ratios and found a marked reduction in schizophrenia. Although serum IFN- $\gamma / \mathrm{IL}-10$ ratios were not associated with psychopathology or symptom severity in schizophrenia as a whole group, they were markedly related to symptom severity at discharge in both genders with schizophrenia. Nevertheless, their associations to symptom severity in both genders were opposite; serum IFN- $\gamma / \mathrm{IL}-10$ ratios were positively associated with symptom severity at discharge in schizophrenic males, but negatively with that in females. It seems that the more Th1 shift (higher IFN- $\gamma / \mathrm{IL}-10$ ) in schizophrenic males, but the more Th2 shift (lower IFN- $\gamma /$ IL-10) in schizophrenic females at admission, the worse their symptoms would be at discharge. Serum IFN$\gamma / \mathrm{IL}-10$ ratios seem to be able to predict treatment outcomes in schizophrenia. In addition, serum IFN- $\gamma /$ IL-10 ratios were also negatively linked to symptom severity at admission and positively associated with differences/changes in symptom severity at discharge in females with schizophrenia. That is, Th2 shift appeared to be related to symptom severity at admission and to be able to predict treatment effects in female schizophrenia.

Both sexes of schizophrenia appeared to have different profiles of Th1/Th2 imbalance. Th1/Th2 imbalance seemed to have different meanings for both genders of schizophrenia. Sex differences in schizophrenia have been attributed to estrogen ${ }^{83}$ more than one decade ago. Several indirect findings have suggested testosterone as a possible treatment modality for schizophrenia ${ }^{84}$. Questions remain how serum IFN- 
$\gamma / \mathrm{IL}-10$ and IL-2/IL-4 ratios interact with sex-hormones to interfere with patients' functioning and negative symptoms/psychopathology and how they are impacted by diverse neuroleptics. Whether or not are serum IFN- $\gamma / \mathrm{IL}-4$ ratios related to the pathology in female schizophrenia and if they are, then how? Whether or not are those altered Th1/Th2 ratios schizophrenia-specific? Further studies are demanded since our findings involved only a relatively small number of subjects.

\section{Acknowledgements}

This investigation was supported by the Theodore Vada Stanley Research Institute. We also appreciatively thank Professor Daisy Lan Hung and Professor Chi-Hung Juan of the Institute of Cognitive Neuroscience of National Central University (Taiwan) for their support in publishing this article.

\section{References}

1. Muller N, Ulmschneider M, Scheppach C, Schwarz MJ, Ackenheil M, Möller HJ, et al. COX-2 inhibition as a treatment approach in schizophrenia: immunological considerations and clinical effects of celecoxib add-on therapy. Eur Arch Psychiatry Clin Neurosci 2004; 254(1): 14-22.

2. Dhiman N, Ovsyannikova IG, Howe RC, Ryan JE, Jacobson RM, Poland GA. Interleukin-4 induced by measles virus and measles-derived peptides as measured by IL-4 receptor-blocking ELISA. J Immunol Methods 2004; 287(1-2): 217-225.

3. Brown AS, Begg MD, Gravenstein S, Schaefer CA, Wyatt RJ, Bresnahan M, et al. Serologic evidence of prenatal influenza in the etiology of schizophrenia. Arch Gen Psychiatry 2004; 61(8): 774-780.

4. Ebert T, Kotler M. Prenatal exposure to influenza and the risk of subsequent development of schizophrenia. Isr Med Assoc J 2005; 7(1): 35-38.
5. Brown AS, Vinogradov S, Kremen WS, Poole JH, Deicken RF, Penner JD, et al. Prenatal exposure to maternal infection and executive dysfunction in adult schizophrenia. Am J Psychiatry 2009; 166(6): 683-690.

6. Bot A, Rodrigo E, Wolfe T, Bot S, Von Herrath MG. Infection-triggered regulatory mechanisms override the role of STAT 4 in control of the immune response to influenza virus antigens. J Virol 2003; 77(10): 5794-5800.

7. Oran AE, Robinson HL. DNA vaccines: influenza virus challenge of a Th2/Tc 2 immune response results in a Th2/Tc1 response in the lung. J Virol 2004; 78(8): 4376-4380.

8. Miller CH, Maher SG, Young HA. Clinical Use of Interferon-gamma. Ann N Y Acad Sci 2009; 1182: 69-79.

9. Hegazy AN, Peine M, Helmstetter C, Panse I, Fröhlich A, Bergthaler A, et al. Interferons direct Th2 cell reprogramming to generate a stable GATA-3(+)T-bet(+) cell subset with combined Th2 and Th1 cell functions. Immunity $2010 ; 32(1): 116-128$.

10. Tang Y, Liao C, Xu X, Song H, Shi S, Yang S. Th1/Th2 Cytokine profiles in G+/G- bacteremia in pediatric hematology/oncology patients. Pediatr Blood Cancer 2011 [Epub ahead of print].

11. Sun L, Yu G, Yang S, Zhang L. Effects of hydrocortisone on the differentiation of human $\mathrm{T}$ helper 2 cells. Scand J Immunol 2011; 73(3): 208-214.

12. Romagnani S. Type $1 \mathrm{~T}$ helper and type $2 \mathrm{~T}$ helper cells: functions, regulation and role in protection and disease. Int J Clin Lab Res 1991; 21(2):152-158.

13. Gattaz WF, Dalgalarrondo P, Schroder HC. Abnormalities in serum concentrations of interleukin-2, interferon-alpha and interferon-gamma in schizophrenia not detected. Schizophr Res 1992; 6(3): 237-241.

14. Buka SL, Tsuang MT, Torrey EF, Klebanoff MA, Wagner RL, Yolken RH. Maternal cytokine levels during pregnancy and adult psychosis. Brain Behav Immun 2001; 15(4):411-420.

15. Kim YK, Lee MS, Suh KY. Decreased interleukin-2 production in Korean schizophrenic patients. Biol Psychiatry 1998; 43(9): 701-704.

16. Kaminska T, Wysocka A, Marmurowska-Michalowska H, Dubas-Slemp H, Kandefer-Szerszen M. Investigation of serum cytokine levels and cytokine production in whole blood cultures of paranoid schizophrenic patients. Arch Immunol Ther Exp (Warsz) 2001; 49(6): 439-445.

17. Xu HM, Wei J, Hemmings GP. Changes of plasma concentrations of interleukin-1 alpha and interleukin-6 with neuroleptic treatment for schizophrenia. Br J Psychiatry 1994; 164(2):251-253. 
18. Barak V, Barak Y, Levine J, Nisman B, Roisman I. Changes in interleukin-1 beta and soluble interleukin-2 receptor levels in CSF and serum of schizophrenic patients. J Basic Clin Physiol Pharmacol 1995; 6(1): 61-69.

19. Schattner A, Cori Y, Hahn T, Sirota P. No evidence for autoimmunity in schizophrenia. J Autoimmun 1996; 9(5):661-666.

20. Haack M, Hinze-Selch D, Fenzel T, Kraus T, Kühn M, Schuld A, et al. Plasma levels of cytokines and soluble cytokine receptors in psychiatric patients upon hospital admission: effects of confounding factors and diagnosis. J Psychiatr Res 1999; 33(5):407-418.

21. Erbagci AB, Herken H, Koyluoglu O, Yilmaz N, Tarakcioglu M. Serum IL-1beta, sIL-2R, IL-6, IL-8 and TNF-alpha in schizophrenic patients, relation with symptomatology and responsiveness to risperidone treatment. Mediators Inflamm 2001; 10(3):109-115.

22. Schmitt A, Bertsch T, Tost H, Bergmann A, Henning $\mathrm{U}, \mathrm{Klimke} \mathrm{A}$, et al. Increased serum interleukin-1beta and interleukin-6 in elderly, chronic schizophrenic patients on stable antipsychotic medication. Neuropsychiatr Dis Treat 2005; 1(2):171-177.

23. Coelho FM, Reis HJ, Nicolato R, Romano-Silva MA, Teixeira MM, Bauer ME, et al. Increased serum levels of inflammatory markers in chronic institutionalized patients with schizophrenia. Neuroimmunomodulation 2008; 15(2): 140-144.

24. O’Brien SM, Scully P, Dinan TG. Increased tumor necrosis factor-alpha concentrations with interleukin-4 concentrations in exacerbations of schizophrenia. Psychiatry Res 2008; 160(3):256-262.

25. Becker D, Kritschmann E, Floru S, Shlomo-David Y, Gotlieb-Stematsky T. Serum interferon in first psychotic attack. Br J Psychiatry 1990; 157:136-138.

26. Kim DJ, Kim W, Yoon SJ, Go HJ, Choi BM, Jun TY, et al. Effect of risperidone on serum cytokines. Int J Neurosci 2001; 111(1-2):11-19.

27. Barry S, Clarke G, Scully P, Dinan TG. Kynurenine pathway in psychosis: evidence of increased tryptophan degradation. J Psychopharmacol 2009; 23(3): 287-294.

28. Rothermundt M, Arolt V, Leadbeater J, Peters M, Rudolf S, Kirchner H. Cytokine production in unmedicated and treated schizophrenic patients. Neuroreport 2000; 11(15):3385-3388.

29. Arolt V, Rothermundt M, Wandinger KP, Kirchner $H$. Decreased in vitro production of interferon-gamma and interleukin-2 in whole blood of patients with schizophrenia during treatment. Mol Psychiatry 2000; 5(2):150-158.
30. Rothermundt M, Arolt V, Weitzsch C, Eckhoff D, Kirchner H. Immunological dysfunction in schizophrenia: a systematic approach. Neuropsychobiology 1998; 37(4): 186-193.

31. Arolt V, Weitzsch C, Wilke I, Nolte A, Pinnow M, Rothermundt $\mathrm{M}$, et al. Production of interferon-gamma in families with multiple occurrence of schizophrenia. Psychiatry Res 1997; 66(2-3):145-152.

32. Wilke I, Arolt V, Rothermundt M, Weitzsch C, Hornberg M, Kirchner H. Investigations of cytokine production in whole blood cultures of paranoid and residual schizophrenic patients. Eur Arch Psychiatry Clin Neurosci 1996; 246(5):279-284.

33. Hornberg M, Arolt V, Wilke I, Kruse A, Kirchner H. Production of interferons and lymphokines in leukocyte cultures of patients with schizophrenia. Schizophr Res 1995; 15(3):237-242.

34. Katila H, Cantell K, Hirvonen S, Rimon R. Production of interferon-alpha and gamma by leukocytes from patients with schizophrenia. Schizophr Res 1989; 2(4-5):361-365.

35. Moises HW, Schindler L, Leroux M, Kirchner H. Decreased production of interferon alpha and interferon gamma in leucocyte cultures of schizophrenic patients. Acta Psychiatr Scand 1985; 72(1):45-50.

36. Potvin S, Stip E, Sepehry AA, Gendron A, Bah R, Kouassi E. Inflammatory cytokine alterations in schizophrenia: a systematic quantitative review. Biol Psychiatry 2008; 63(8):801-808.

37. Garver DL, Tamas RL, Holcomb JA. Elevated interleukin-6 in the cerebrospinal fluid of a previously delineated schizophrenia subtype. Neuropsychopharmacology 2003; 28(8):1515-1520.

38. Zhang XY, Zhou DF, Zhang PY, Wu GY, Cao LY, Shen YC. Elevated interleukin-2, interleukin-6 and interleukin-8 serum levels in neuroleptic-free schizophrenia: association with psychopathology. Schizophr Res 2002; 57(2-3):247-258.

39. van Kammen DP, McAllister-Sistilli CG, Kelley ME, Gurklis JA, Yao JK. Elevated interleukin-6 in schizophrenia. Psychiatry Res 1999; 87(2-3):129-136.

40. Lin A, Kenis G, Bignotti S, Tura GJ, De Jong R, Bosmans E, et al. The inflammatory response system in treatment-resistant schizophrenia: increased serum interleukin-6. Schizophr Res 1998; 32(1):9-15.

41. Naudin J, Capo C, Giusano B, Mege JL, Azorin JM. A differential role for interleukin-6 and tumor necrosis factor-alpha in schizophrenia? Schizophr Res 1997; 26(23):227-233. 
42. Frommberger UH, Bauer J, Haselbauer P, Fraulin A, Riemann D, Berger M. Interleukin-6-(IL-6) plasma levels in depression and schizophrenia: comparison between the acute state and after remission. Eur Arch Psychiatry Clin Neurosci 1997; 247(4):228-233.

43. Naudin J, Mege JL, Azorin JM, Dassa D. Elevated circulating levels of IL-6 in schizophrenia. Schizophr Res 1996; 20(3):269-273.

44. Maes M, Bosmans E, Calabrese J, Smith R, Meltzer HY. Interleukin-2 and interleukin-6 in schizophrenia and mania: effects of neuroleptics and mood stabilizers. J Psychiatr Res 1995; 29(2):141-152.

45. Maes M, Meltzer HY, Bosmans E. Immune-inflammatory markers in schizophrenia: comparison to normal controls and effects of clozapine. Acta Psychiatr Scand 1994; 89(5):346-351.

46. Shintani F, Kanba S, Maruo N, Nakaki T, Nibuya M, Suzuki E, et al. Serum interleukin-6 in schizophrenic patients. Life Sci 1991; 49(9):661-664.

47. Muller N, Riedel M, Gruber R, Ackenheil M, Schwarz MJ. The immune system and schizophrenia. An integrative view. Ann N Y Acad Sci 2000; 917: 456-467.

48. Schwarz MJ, Chiang S, Muller N, Ackenheil M. Thelper-1 and T-helper-2 responses in psychiatric disorders. Brain Behav Immun 2001; 15(4):340-370.

49. Schwarz MJ, Muller N, Riedel M, Ackenheil M. The Th2-hypothesis of schizophrenia: a strategy to identify a subgroup of schizophrenia caused by immune mechanisms. Med Hypotheses 2001; 56(4):483-486.

50. Zhou X, Schmidtke P, Zepp F, Meyer CU. Boosting interleukin-10 production: therapeutic effects and mechanisms. Curr Drug Targets Immune Endocr Metabol Disord 2005; 5(4):465-475.

51. O'Garra A, Murphy K. Role of cytokines in determining T-lymphocyte function. Curr Opin Immunol 1994; 6(3):458-466.

52. Donckier V, Abramowicz D, Bruyns C, Florquin S, Vanderhaeghen ML, Amraoui Z, et al. IFN-gamma prevents Th2 cell-mediated pathology after neonatal injection of semiallogenic spleen cells in mice. J Immunol 1994; 153(6):2361-2368.

53. Abehsira-Amar O, Gibert M, Joliy M, Theze J, Jankovic DL. IL-4 plays a dominant role in the differential development of Tho into Th1 and Th2 cells. J Immunol 1992; 148(12):3820-3829.

54. Scott P. IFN-gamma modulates the early development of Th1 and Th2 responses in a murine model of cutaneous leishmaniasis. J Immunol 1991; 147(9):3149-3155.
55. Wagner B, Burton A, Ainsworth D. Interferongamma, interleukin- 4 and interleukin-10 production by $\mathrm{T}$ helper cells reveals intact Th1 and regulatory TR1 cell activation and a delay of the Th2 cell response in equine neonates and foals. Vet Res 2010;41(4):47.

56. Avgustin B, Wraber B, Tavcar R. Increased Th1 and Th2 immune reactivity with relative Th2 dominance in patients with acute exacerbation of schizophrenia. Croat Med J 2005; 46(2):268-274.

57. Kim YK, Myint AM, Lee BH, Han CS, Lee HJ, Kim DJ, et al. Th1, Th2 and Th3 cytokine alteration in schizophrenia. Prog Neuropsychopharmacol Biol Psychiatry 2004; 28(7):1129-1134

58. Jensen KD, Sercarz EE, Gabaglia CR. Altered peptide ligands can modify the Th2 $\mathrm{T}$ cell response to the immunodominant 161-175 peptide of LACK (Leishmania homolog for the receptor of activated C kinase). Mol Immunol 2009; 46(3):366-374.

59. Avery PR, Hoover EA. Gamma interferon/interleukin 10 balance in tissue lymphocytes correlates with down modulation of mucosal feline immunodeficiency virus infection. J Virol 2004; 78(8):4011-4019.

60. Watanabe Y, Nunokawa A, Shibuya M, Kaneko N, Nawa H, Someya T. Association study of interleukin 2 (IL2) and IL4 with schizophrenia in a Japanese population. Eur Arch Psychiatry Clin Neurosci 2008; 258(7):422-427.

61. World Health Organization. The ICD-10 classification of mental and behavioural disorders: Clinical descriptions and diagnosis guidelines. Geneva 1994.

62. American Psychiatric Association. Diagnostic and Statistical Manual of Mental Disorders, 4th ed. Washington, DC: American Psychiatric Press; 1994.

63. Kay SR, Opler LA, Lindenmayer JP. Reliability and validity of the positive and negative syndrome scale for schizophrenics. Psychiatry Res 1988; 23(1):99-110.

64. Guy W (Ed.). ECDEU Assessment Manual for Psychopharmacology. Rockville, Maryland: Department of Health, Education, and Welfare; 1976.

65. Garcia-Miss Mdel R, Perez-Mutul J, Lopez-Canul B, Solís-Rodríguez F, Puga-Machado L, Oxté-Cabrera A, et al. Folate, homocysteine, interleukin-6, and tumor necrosis factor alfa levels, but not the methylenetetrahydrofolate reductase C677T polymorphism, are risk factors for schizophrenia. J Psychiatr Res 2010; 44(7):441-446.

66. Nunes SO, Matsuo T, Kaminami MS, Watanabe MA, Reiche EM, Itano EN. An autoimmune or an inflammatory process in patients with schizophrenia, schizoaffective disorder, and in their biological relatives. Schizophr Res 2006; 84(1):180-182. 
67. Zhang XY, Zhou DF, Cao LY, Zhang PY, Wu GY, Shen YC. Changes in serum interleukin-2, -6 , and -8 levels before and during treatment with risperidone and haloperidol: relationship to outcome in schizophrenia. J Clin Psychiatry 2004; 65(7):940-947.

68. Zhang X, Zhou DF, Zhang PY, Wu GY, Cao LY, Shen YC. Elevated interleukin-2, interleukin-6 and interleukin-8 serum levels in neuroleptic-free schizophrenia: association with psychopathology. Schizophr Res 2002; 57(23):247-258

69. Akiyama K. Serum levels of soluble IL-2 receptor alpha, IL-6 and IL-1 receptor antagonist in schizophrenia before and during neuroleptic administration. Schizophr Res 1999; 37(1):97-106.

70. Kim YK, Myint AM, Verkerk R, Scharpe S, Steinbusch H, Leonard B. Cytokine changes and tryptophan metabolites in medication-naive and medication-free schizophrenic patients. Neuropsychobiology 2009; 59(2):123-129.

71. Baker I, Masserano J, Wyatt RJ. Serum cytokine concentrations in patients with schizophrenia. Schizophr Res 1996; 20(1-2):199-203.

72. Trenerry MK, Della Gatta PA, Larsen AE, Garnham AP, Cameron-Smith D. Impact of resistance exercise training on interleukin- 6 and JAK/STAT in young men. Muscle Nerve 2011; 43(3):385-392.

73. Freudenreich O, Brockman MA, Henderson DC, Evins AE, Fan X, Walsh JP, et al. Analysis of peripheral immune activation in schizophrenia using quantitative reverse-transcription polymerase chain reaction (RT-PCR). Psychiatry Res 2010; 176(2-3):99-102.

74. Zhang XY, Zhou DF, Qi LY, Chen S, Cao LY, Chen da $\mathrm{C}$, et al. Superoxide dismutase and cytokines in chronic patients with schizophrenia: association with psychopathology and response to antipsychotics. Psychopharmacology (Berl) 2009; 204(1):177-184 .

75. Fairweather D, Frisancho-Kiss S, Rose NR. Sex differences in autoimmune disease from a pathological perspective. Am J Pathol 2008; 173(3):600-609.

76. Mouton PR, Kelley-Bell B, Tweedie D, Spangler EL, Perez E, Carlson OD, et al. The effects of age and lipopolysaccharide (LPS)-mediated peripheral inflammation on numbers of central catecholaminergic neurons. Neurobiol Aging 2010 [Epub ahead of print].
77. Shamsi S, Lau A, Lencz T, Burdick KE, DeRosse P, Brenner R, et al. Cognitive and symptomatic predictors of functional disability in schizophrenia. Schizophr Res 2011; 126(1-3):257-264.

78. Ganguli R, Brar JS, Chengappa KR, DeLeo M, Yang $\mathrm{ZW}$, Shurin G, et al. Mitogen-stimulated interleukin-2 production in never-medicated, first-episode schizophrenic patients. The influence of age at onset and negative symptoms. Arch Gen Psychiatry 1995; 52(8):668-672.

79. Bresee C, Rapaport MH. Persistently increased serum soluble interleukin-2 receptors in continuously ill patients with schizophrenia. Int J Neuropsychopharmacol 2009; 12(6):861-865.

80. Martin JT. Sexual dimorphism in immune function: the role of prenatal exposure to androgens and estrogens. Eur J Pharmacol 2000; 405(1-3): 251-261.

81. Giron-Gonzalez JA, Moral FJ, Elvira J, García-Gil D, Guerrero F, Gavilán I, et al. Consistent production of a higher TH1:TH2 cytokine ratio by stimulated T cells in men compared with women. Eur J Endocrinol 2000; 143(1):31-36.

82. Gabbay V, Klein RG, Alonso CM, Babb JS, Nishawala M, De Jesus G, et al. Immune system dysregulation in adolescent major depressive disorder. $\mathrm{J}$ Affect Disord 2009; 115(1-2):177-182.

83. Fink G, Sumner BE, Rosie R, Grace O, Quinn JP. Estrogen control of central neurotransmission: effect on mood, mental state, and memory. Cell Mol Neurobiol 1996; 16(3):325-344.

84. Ko YH, Lew YM, Jung SW, Joe SH, Lee CH, Jung $\mathrm{HG}$, et al. Short-term testosterone augmentation in male schizophrenics: a randomized, double-blind, placebo-controlled trial. J Clin Psychopharmacol 2008; 28(4):375-383.

Author for correspondence:

Markus Schwarz

PsychoNeuroImmunology and Therapeutic Drug Monitoring Section

Psychiatric Hospital of Munich University

Nussbaumstr. 7, 80336 Munich, Germany

Phone: +498951602761.

Fax: +498951605496

E-mail: Markus.Schwarz.Munich@googlemail.com 